\title{
On the vortical motions in the Black Sea obtained by the 3-D hydrothermodynamical numerical model
}

\author{
D. I. Demetrashvili, D. U. Kvaratskhelia, and A. I. Gvelesiani \\ Mikheil Nodia Institute of Geophysics, 1, Alexidze Str., 0193 Tbilisi, Georgia \\ Received: 16 June 2007 - Revised: 18 December 2007 - Accepted: 19 December 2007 - Published: 10 April 2008
}

\begin{abstract}
Some results of simulation of the Black Sea circulation with consideration of forcing of different averaged wind types by using 3-D prognostic baroclinic model are presented. The results allow us to consider all depth of the sea basin consisting of some relatively homogeneous sub-layers. Within each of them general circulation processes practically do not change by depth, but essentially change from layer to layer. Such character of changeability interpreted by us as a steepness of the Black Sea general circulation takes place in majority cases of climatic atmospheric wind forcing. In the present paper results are analyzed on an example of forcing of January atmospheric cyclonic vortex with $\sim 250 \mathrm{~km}$ diameter. Under such forcing the Ekman surface layer of $\sim 12 \mathrm{~m}$ thickness is created. The cyclonic vortex formed in the east part of the Black Sea, which is Taylor-Proudman potential vortex with vertical cylindrical configuration, is described in detail. The vertical distribution of vortex characteristics are given in figures: Brunt-Väisälä frequency and Richardson number taken near the vortex wall with maximal velocity. The viable vortexes are characterized by introduced the universal Reynolds number $\mathrm{Re}^{\bullet}$.
\end{abstract}

\section{Introduction}

The Black Sea because of its specific hydrological structure many decades is the focus of many oceanologic researches and therefore is one of the most well investigated water basin of the World Ocean. The study of many aspects of formation and evolution of 3-D hydrophysical fields in the Black Sea depending on external and internal physical factors (wind and thermal forcing, solar radiation absorption by sea water, water turbidity, etc.) has significantly increased during the last decade (e.g., Demyshev and Korotaev, 1996; Staneva et al., 2001; Beckers et al., 2002; Korotaev et al., 2003; Kordzadze and Demetrshvili, 2004; Kara et al., 2005a, b, c; Kordzadze et al., 2007). Theoretical investigations of

Correspondence to: D. I. Demetrashvili

(dikas709@yahoo.com) dynamical processes in the Black Sea are based on different finite difference models which differ from each other by used coordinate system, methods of solution, grid parameters, parametrization of turbulence, etc. Staneva et al. (2001) applied the DieCast model that is z-level, primitive, hydrostatic model. Korotaev et al. (2003) used a shellow water model with assimilation 7 year- long (1992-1999) altimeter data to simulate the seasonal, interannual and mesoscale features of the upper layer circulation in the Black Sea. In our opinion the special attention deserves the eddy-resolving ( $\sim 3.2 \mathrm{~km}$ resolution) Hybrid Coordinate Ocean Model (HY$\mathrm{COM}$ ), which is introduced to the Black Sea for the first time by Kara et al. (2005a). The model uses a new solar radiation penetration scheme which is very important in the process of formation of thermal regime in the upper layer of the Black Sea. By using HYCOM model Kara et al. (2005a, b) carried out extensive researches on sensitivity of sea surface temperature and upper layer circulation to sea water turbidity. HYCOM model was also applied for studying of Black Sea mixed layer sensitivity to atmospheric wind (eight wind forcing products were used) and thermal forcing (Kara et al., 2005c). This paper shows the importance of using high frequency wind forcing.

Despite of rather high level of our knowledge in hydro and thermodynamic processes in the Black Sea, we consider that some problems concerning hydrological structure of the sea, are not solved completely. Among such problems it is necessary to note importance of studying of vertical structure of the Black Sea general circulation (including deep sea levels), especially in conditions of alternation of different types of an atmospheric wind, as the variability of atmospheric processes plays significant role in temporal-space changes of the hydro and thermodynamical parameters of seas, among them - in formation of turbulent vortexes, which represent significant elements of its general circulation. In some above mentioned papers the response of the Black Sea circulation to nonstationarity of atmospheric processes is studied, but to investigate vertical structure of general circulation in detail including deep sea levels is not main object of interest.

Published by Copernicus Publications on behalf of the European Geosciences Union. 


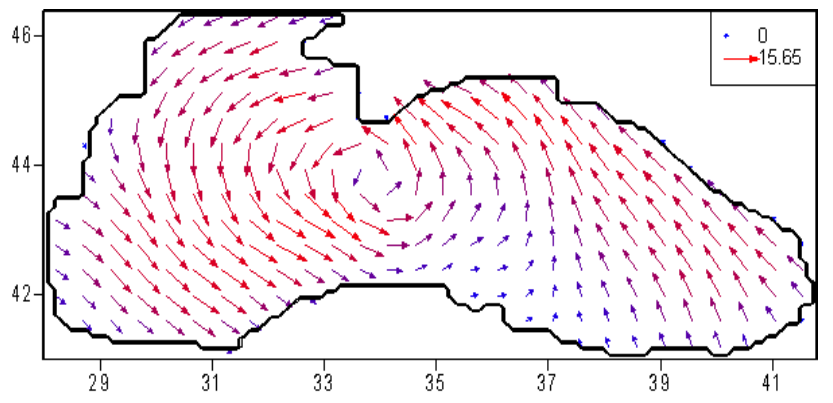

Fig. 1. Wind stress field on the Black Sea surface used in the model.

The main goal of this paper is to study the vertical changeability of the Black Sea general circulation including turbulent vortex system, distribution of their turbulent and hydrophysical characteristics. With this purpose the original baroclinic model was used (Kordzadze and Demetrashvili, 2004) with taken into account the forcing of different averaged atmospheric wind types developed above the Black Sea (Atlas of excitement and wind of the Black Sea, 1969; Kordzadze et al., 2000).

\section{The model description and method of solution}

The model is based on a primitive equation system of ocean hydrothermodynamics in hydrostatic approximation (Kordzadze and Demetrashvili, 2004) and uses z-level coordinates. The model takes into account: atmospheric wind and thermohaline forcing, water exchange with the Mediterranean Sea and inflow of the Danube River, the absorption of solar radiation by the sea surface layer, space-temporal variability of horizontal and vertical turbulent exchange. Atmospheric forcing is taken into account by boundary conditions on the sea surface considered as a rigid surface, where the wind stress components, temperature and salinity were given as known functions.

For solution of the problem a two-cycle splitting method was used (Marchuk, 1974).

\section{Key model parameters}

The surface of the Black Sea was covered with a grid with the constant steps equal to $10 \mathrm{~km}$. The quantity of points along axes $\mathrm{x}$ and $\mathrm{y}$ was 113 and 56, respectively. On a vertical the non-uniform grid with 32 calculated levels on different depths: $2,4,6,8,12,16,26,36,56,86,136,206$, $306, \ldots, 2206 \mathrm{~m}$ were considered. the time step is equal to $1 \mathrm{~h}$. Values of other parameters are given by Kordzadze and Demetrashvili (2004).

\section{Results of numerical experiment}

In the numerical experiment the integration started on the 1 January and proceeded one modeling year. As initial conditions annual mean climatic fields obtained by the same model were used. Wind forcing variability was reduced to continuous alternation of 24 types of averaged atmospheric wind within one modeling year. These types of atmospheric circulation were taken from (Atlas of excitement and wind of the Black Sea, 1969). Duration of action of each wind types was 10-60 $\mathrm{h}$ and they differed from each other by direction, module, and repeatability (Kordzadze et al., 2000). Numerical experiments showed that under the influence of non-stationarity of atmospheric processes the circulation in the upper layer of the Black Sea is characterized by significant qualitative and quantitative changes and within one year a continuous transformation of a sea current system is evident (Kordzadze and Demetrashvili, 2004).

The present paper focuses on studying of vertical structure of the Black Sea general circulation in conditions of nonstationarity of atmospheric processes. The analysis of model results shows that, the general circulation of the Black Sea with depth has steepness structure at the majority types of a wind. It enables to consider all depth of the sea basin consisting of some relatively homogeneous sub-layers. Within each of them the sea circulation practically does not change by depth, but essentially changes from layer to layer.

In the present paper results are analyzed only on an example (because of restriction of paper's volume) of forcing of January atmospheric circulation $(10-15 \mathrm{~m} / \mathrm{s})$ during the time period $451-469 \mathrm{~h}$, when atmospheric cyclonic vortex with $\sim 250 \mathrm{~km}$ diameter was allocated in the central part of the sea basin (Fig. 1).

These homogeneous sub-layers obtained in the numerical experiment were following: $1-16 \mathrm{~m}, 26-86 \mathrm{~m}, 136-306 \mathrm{~m}$, $406-906 \mathrm{~m}$ at the time moments $t=459 \mathrm{~h}$ and $1-12 \mathrm{~m}, 16-$ $86 \mathrm{~m}, 136-306 \mathrm{~m}, 406-906 \mathrm{~m}$ at the time moment $t=469 \mathrm{~h}$. Figures 2 and 3 show computed current fields in these sublayers at the time moments $t=459$ and $t=469 \mathrm{~h}$, respectively and clearly demonstrate the steepness character of circulation. From these figures it is visible that under influence of the intensive cyclonic atmospheric circulation the sea circulation in the most upper (mixed) layer has divergence character. With increasing of depth the sea circulation is transformed in cyclonic motion and approximately from $86 \mathrm{~m}$ the system of turbulent vortexes is expressed. Analysis of results also showed that variability of a wind regime above the sea basin makes significant changes in a circulating regime of the Black Sea, but the steepness structure basically is kept.

From Fig. 4, which illustrates computed temperature and salinity fields in the surface layer at $t=469 \mathrm{~h}$, it is visible that main features of thermohaline fields are in a good agreement with results known from experimental and theoretical investigations (Demyshev and Korotaev, 1996; Oguz et al., 1995). 

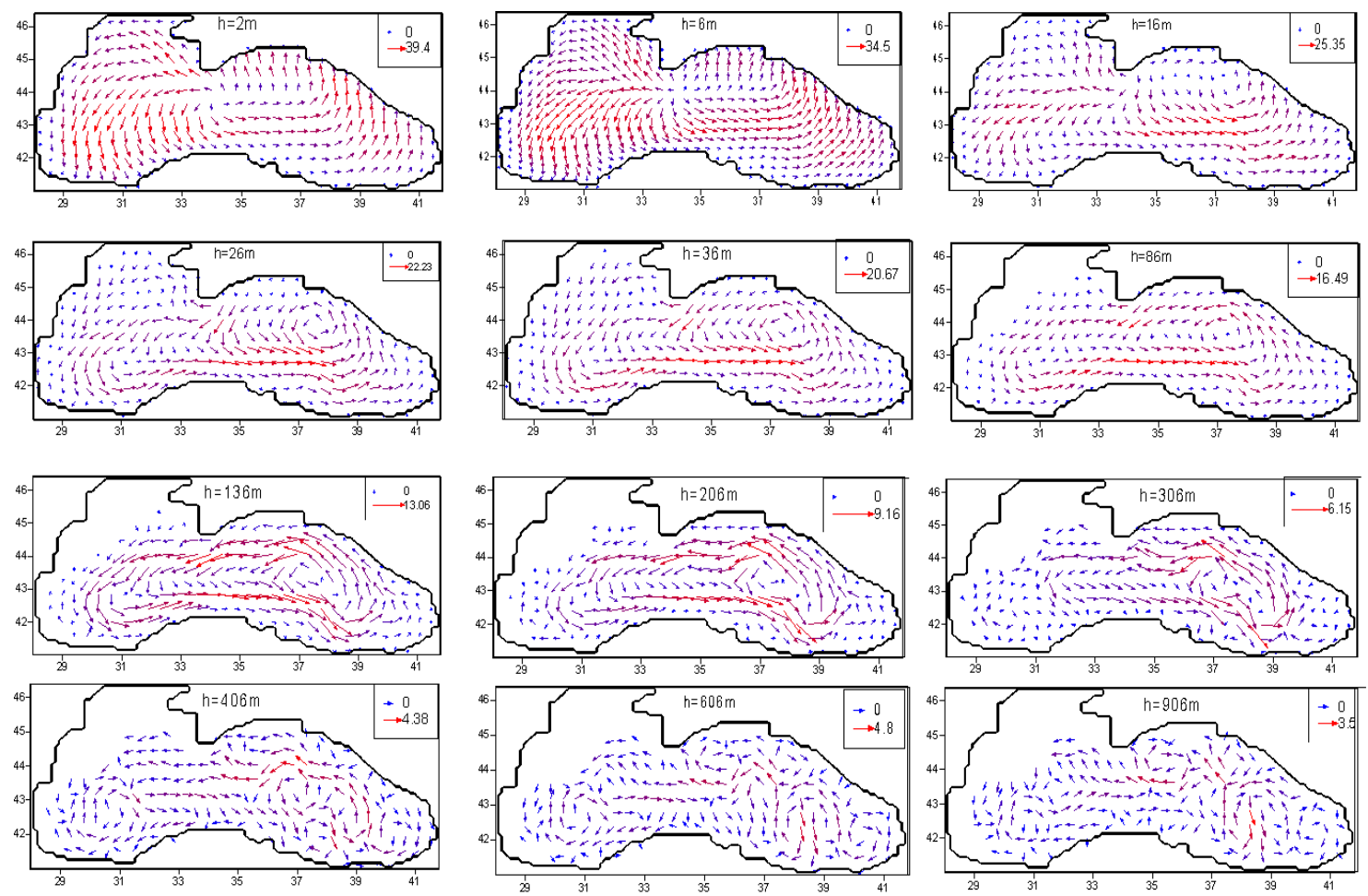

Fig. 2. Calculated current field $(\mathrm{cm} / \mathrm{s})$, in the following homogeneous sub-layers: $1-16 \mathrm{~m}, 26-86 \mathrm{~m}, 136-306 \mathrm{~m}, 406-906 \mathrm{~m}$, at $t=459 \mathrm{~h}$ (January).
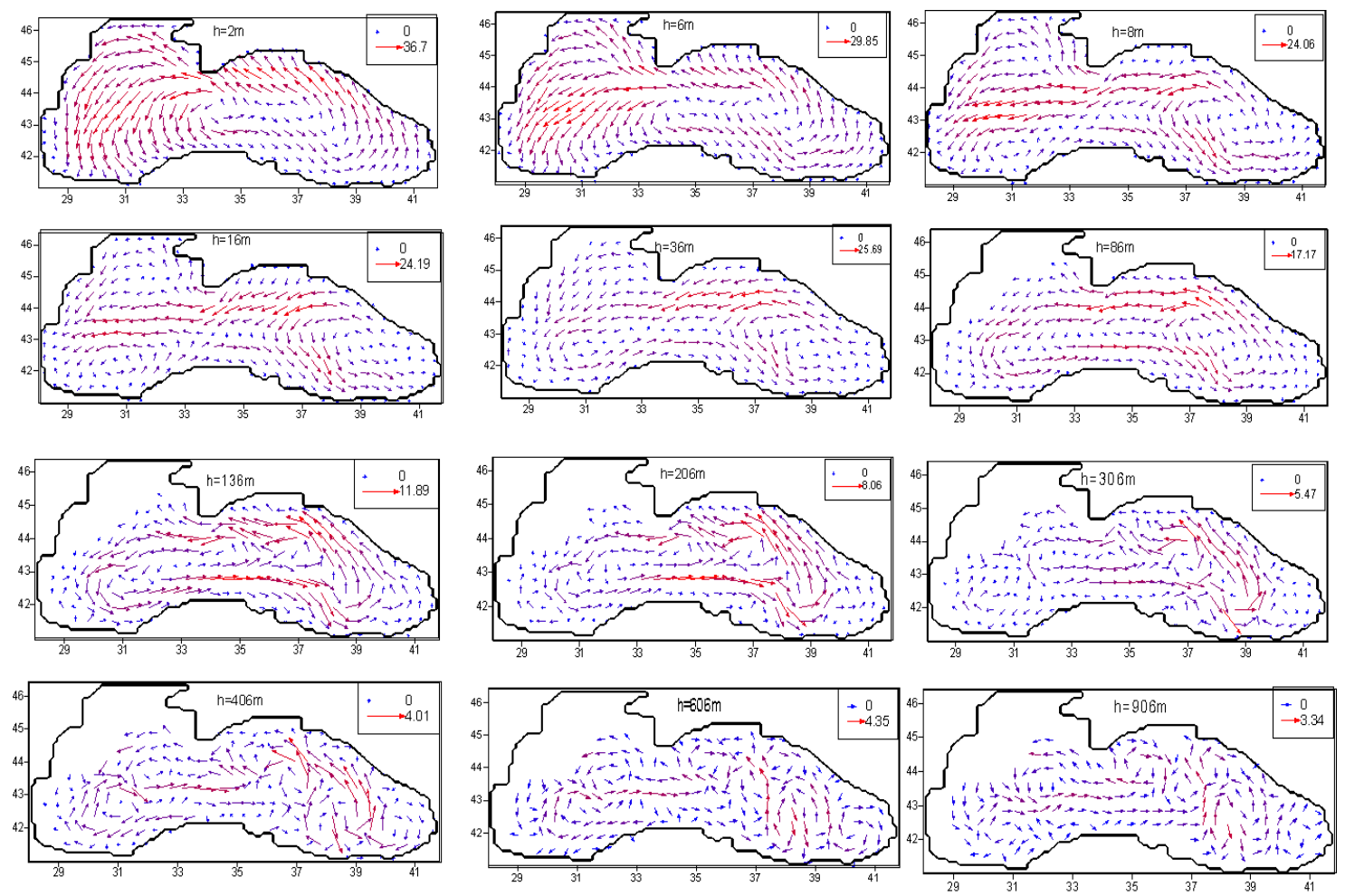

Fig. 3. Calculated current field $(\mathrm{cm} / \mathrm{s})$, in the following homogeneous sub-layers: 1-12 $\mathrm{m}, 16-86 \mathrm{~m}, 136-306 \mathrm{~m}, 406-906 \mathrm{~m}$, at $t=469 \mathrm{~h}$ (January). 
(a)

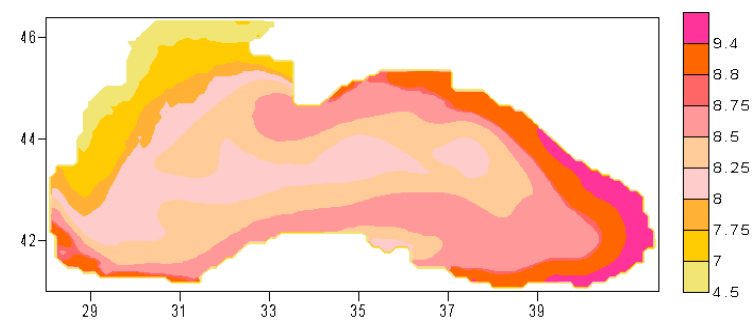

(b)

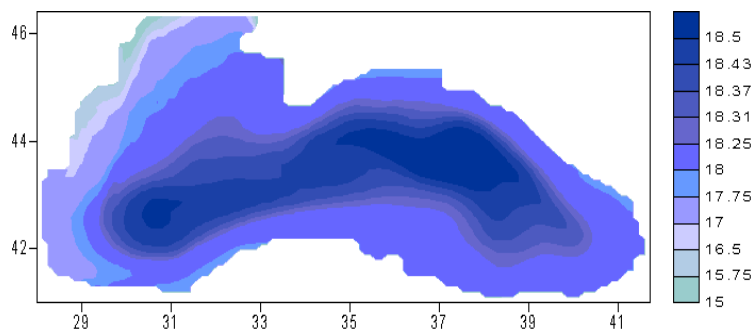

Fig. 4. (a) The temperature $\left({ }^{\circ} \mathrm{C}\right)$ and (b) the salinity (\%o) fields at depth of $6 \mathrm{~m}$ at $t=469 \mathrm{~h}$.

(a)

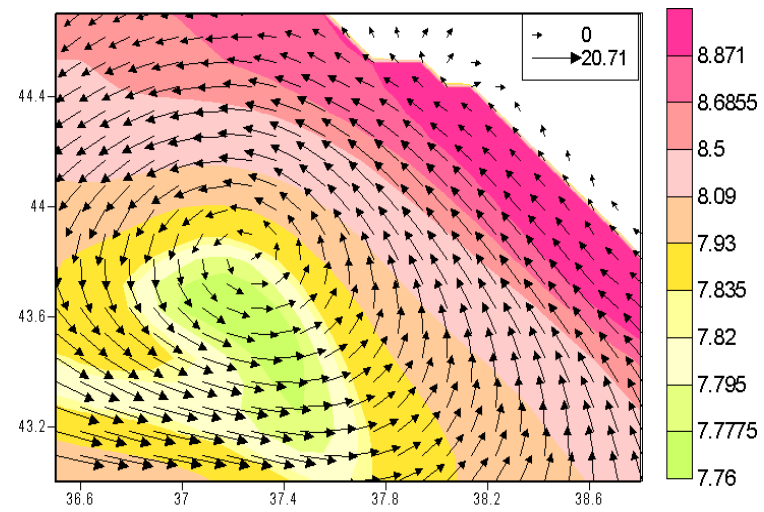

(b)

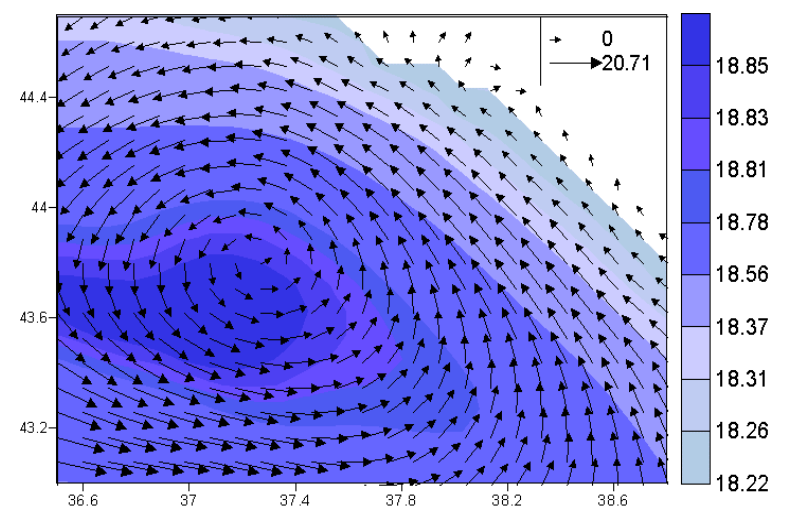

Fig. 5. The vortex from Fig. $2 \mathrm{~b}$ allocated in $36^{\circ} 5^{\prime}-38^{\circ} 8^{\prime}$ E, $43^{\circ}-44^{\circ} 7^{\prime}$ N. (a) Temperature $\left({ }^{\circ} \mathrm{C}\right)$; (b) Salinity (\%o).

(a)

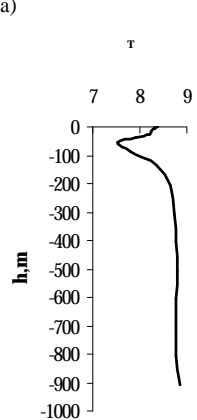

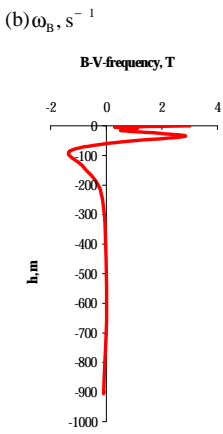

(c) $\mathrm{Ri}$

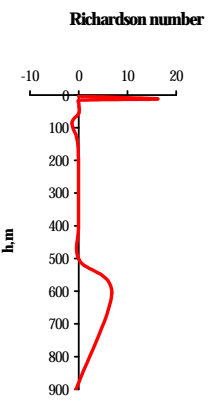

Fig. 6. Vertical distributions: (a) of the temperature, (b) the BruntVäisälä frequency, (c) the Richardson number.

\section{Turbulent characteristics of the vortex}

As it was above mentioned, the separate vortexes are at the center of our attention. To demonstrate clearly cyclonic vortex observed in Fig. $2 \mathrm{~b}$ in the eastern part of the basin (with coordinates: longitude $36^{\circ} 5^{\prime}-38^{\circ} 8^{\prime}$, latitude $43^{\circ}-44^{\circ} 7^{\prime}$ ), this vortex is shown in the increased form in Fig. 5. The verti-

cal distributions of the following parameters - the temperature, the Brunt-Väisälä frequency and the Richardson number taken near the vortex wall where velocity is maximal, are given in Fig. 6 (the Brunt-Väisälä frequencies are multiplied by 100 , the Richardson numbers divided by 100 ).

This vertical vortex, having cylindrical form, in the range of depths $z=36-86 \mathrm{~m}$, longitude $36^{\circ} 5^{\prime}-38^{\circ} 8^{\prime}$, latitude $43^{\circ}-44^{\circ} 7^{\prime}$, similar the Taylor-Proudman potential vortex, is streamlined by the main Black Sea current, where the mean velocity $\bar{V}=10.2 \mathrm{~cm} / \mathrm{s}$, the turbulent viscosity $\bar{\mu}=8.1 \times 10^{7} \mathrm{~cm}^{2} / \mathrm{s}$, the mean universal Reynolds $\overline{\mathrm{Re}} \bullet 5.4$ (Gvelesiani, 2005; Gvelesiani and Kvaratskhelia, 2006), volume transport carried around the vortex equals to $Q \approx 0.4 \mathrm{~Sv}$. Figure $6 \mathrm{c}$ shows the stable and non-stable levels. The above mentioned pillars (turbulent tubes) depth changing some times (2-3) are particularly also reflected in the changing of the turbulent characteristics with depth.

\section{Conclusions}

3-D baroclinic prognostic, z-level, hydrostatic model for investigation of vertical structure of the Black Sea general cir- 
culation is used. Results of modelling show that in the Black Sea circulation has steepness structure with depth and increasing of an intensity of vortex motion by the depth is observed. Variability of a wind regime above the sea basin makes significant changes in a circulating regime of the Black Sea, but the steepness structure basically is kept.

The cyclonic vortex formed in the east part of the Black Sea, which is Taylor-Proudman potential vortex with vertical cylindrical configuration, is described in detail.

Edited by: P. Fabian

Reviewed by: B. Kara and G. Aburjania

\section{References}

Atlas of excitement and a wind of the Black Sea, Gidrometeoizdat, Leningrad, 112 pp., 1969 (in Russian).

Beckers, J. M., Gregoire, M., Nihoul, J. C. J., Stanev, E. V., Staneva, J., and Lancelot, C.: Modelling the Danube-influenced shelf of the Black Sea. I: Hydrodynamical processes simulated by 3-D and box models, Estuarine, Coastal and Shelf Sci., 54, 453-472, 2002.

Demyshev, S. G. and Korotaev, G. K.: Numerical modeling of the seasonal course of the synoptic variability of the Black Sea, Izv. RAN, Atmospheric and Oceanic Physics, 32, 1, 108-116, 1996 (in Russian).

Gvelesiani, A. I.: The law of four universal units and eddy characteristics of vortical motions in different mediums, J. Georgian Geophys. Soc., 10B, 3-19, 2005.

Gvelesiani, A. and Kvaratskhelia, D.: To the problem of characteristics of turbulent vortex motions in the Black Sea, Bulletin Georgian National Acad. Sci., 174, 1, 75-77, 2006.

Kara, A. B., Wallcraft, A. J., and Hurlburt, H. E.: A New Solar Radiation Penetration Scheme for Use in Ocean Mixed Layer Studies: An Application to the Black Sea Using a Fine-Resolution Hybrid Coordinate Ocean Model (HYCOM), J. Phys. Oceanogr., 35, 13-32, 2005a.
Kara, A. B., Wallcraft, A. J., and Hurlburt, H. E.: Sea Surface Temperature Sensitivity to Water Turbidity from Simulations of the Turbid Black Sea Using HYCOM, J. Phys. Oceanogr., 35, 33-54, $2005 b$.

Kara, A. B., Hurlburt, H. E., Wallcraft, A. J., and Bourassa, M. A.: Black Sea Mixed Layer Sensitivity to Various Wind and Thermal Forcing Products on Climatological Time Scales, J. Climate, 18, 5266-5293, 2005c.

Korotaev, G., Oguz, T., Nikiforov, A., and Koblinsky, C.: Seasonal, interannual, and mesoscale variability of the Black Sea upper layer circulation derived from altimeter data, J. Geophys. Res., 108(C4), 3122, doi:10.1029/2002JC001508, 2003.

Kordzadze, A., Tavartkiladze, K., and Kvaratskhelia, D.: A structure of the wind continuous field on the Black Sea surface, J. Georgian Geophys. Soc., 5b, 28-37, 2000.

Kordzadze, A. A. and Demetrashvili, D. I.: Numerical modeling of inner-annual variability of hydrological regime of the Black Sea by alternation of different types of winds above its surface, Proc. of the 30th Intern. Conference Pacem in Maribus. A Year after Johannesburg, Ocean Governance and Sustainable Development: Ocean end Coasts - a Glimpse into the Future, 27-30 October 2003, Kiev, Ukraine, 495-505, 2004.

Kordzadze, A. A., Demetrashvili, D. I., and Surmava, A. A.: About circulation in the Blak Sea at very strong and weak winds, Meteorologia i gidrologia, 9, 58-64, 2007 (in Russian).

Marchuk, G. I.: The numerical solution of the problems of the atmosphere and ocean dynamics, L.: Gidrometeoizdat, 303 pp., 1974 (in Russian).

Oguz, T. A. and Malanotte Rizzoli, A. D.: Wind and thermohaline circulation of the Black Sea driven by yearly mean climatological forcing, J. Geophys. Res., 100(C4), 6845-6863, 1995.

Staneva, J. V., Dietrich D. E., Stanev E. V., and Bowman M. J.: Rim current and coastal eddy mechanisms in an eddy-resolving Black Sea general circulation model, J. Mar. Syst., 31, 137-157, 2001 (in Russian). 